\title{
Experiencing memory museums in Berlin. The Otto Weidt Workshop for the Blind Museum and the Jewish Museum Berlin
}

\author{
Ana Souto*
}

\begin{abstract}
This article explores memory studies from the audience's perspective, focusing on the perception of Holocaust narratives in two museums in Berlin. This research builds on and contributes to a number of emerging issues in memory studies, tourism perception and museum design: the debate on experiential authenticity, Dark Tourism, and the analysis of memory studies from the perspective of the user. The main data facilitating the analysis is based on responses shared on TripAdvisor; the case studies being the Otto Weidt Workshop for the Blind Museum and the Jewish Museum Berlin. The analysis of these museums, focusing on their narratives, design features and comments from visitors, will highlight a potential shift from the traditional object-focused museum, to a phenomenological subjectfocused one. It will be argued, then, that the understanding and consumption of authenticity encompasses a very flexible definition, not only based on the nature of the objects exhibited, but on the production of authentic experiences.
\end{abstract}

Keywords: memory museums; experiential authenticity; Holocaust narratives.

\section{Introduction}

This article explores a particular relationship between architecture, memory and authenticity, focusing on visitors' descriptions of their emotional responses and experiential authenticity of two memory museums in Berlin: the Otto Weidt Workshop for the Blind Museum (OWM) and the Jewish Museum Berlin (JMB). In doing so, I seek to contribute to a growing questioning of traditional understandings of Dark Tourism which privilege its focus on death as its strongest characteristic and which are, as a consequence, concerned with the ethical ramifications of this interest. Like others, I am concerned with understanding instead what it is that visitors actually say they experience at these sites. My own contribution to these arguments is to focus on the role of architecture and exhibition design in the production of an experience which supports the development of a more empathetic understanding of past atrocities rather than assuming their interest is driven by a fascination with death itself.

Dark Tourism has been identified by several authors as a particular area of interest for tourists who purposely seek to engage with macabre spaces. This has been proven to be the case in certain cases (Podoshen 2013), but equally, other studies have questioned the validity of such arguments, analyzing historical landmarks connected with death (Osbaldiston and Petray, 2011). This study aligns with this approach: Berlin, as a tourist destination, offers a series of museums and sites of interest which are irrevocably connected with death and suffering. However, these spaces are ultimately essential to understand the history of recent Germany, and as a result, it is difficult to agree with the idea that these visitors are drawn to Berlin just to experience the macabre. The analysis of the comments left by visitors to two museums in Berlin reveal an interest in the pedagogy of the museum, in learning the history of Germany. Moreover, this data also demonstrates a significant shift towards the phenomenological turn in museology: tourists also want to have a more emotional experience when visiting museums (Hein 2000). This aligns with a new museology which prioritizes how architectural space and exhibition design impact on the ability of visitors to develop a prosthetic memory (Arnold-de Simine 2013). 
This article aims to contribute to these debates focusing on an exploration of the relations between varying understandings of authenticity (on the part of exhibition producers and exhibition visitors), the role of memory, and the impact of design features enhancing a sense of prosthetic memory. The analysis of two museums in relation to the three issues concerned will introduce a more thorough understanding of the contemporary experience of museums, their narratives and consumption, based on the perception of the visitors' experiences as described in their reviews. The analysis highlights the following aspects: first, the narrative of these museums in connection with the authenticity of their respective locations; second, the prosthetic memory of the event commemorated, and how this is enhanced by the design features; and finally, responses from the audience (motivation, rating and recommendation to others), as collated from the tourist website TripAdvisor (TA). ${ }^{1}$

The case studies were selected because even though both are Holocaust museums in Berlin, they have significant differences, such as the style of architecture, scale and location within the city, and more importantly, the focus of their narratives. On the one hand, the JMB explores two parallel narratives: the contribution of the Jewish community to Berlin (exhibition), and the experience and memory of the Holocaust (architectural design), involving significant contradictions that impact on the experience of the museum. The OWM, on the other hand, portrays an unknown narrative: a silent hero who tried to help his Jewish workers.

\section{A multidisciplinary conceptual framework}

\section{Dark Tourism}

The present study builds on and contributes to the debate on the phenomena of Dark Tourism, connecting also with the concept of Difficult Heritage (Logan and Reeves 2009) as well as with studies on the tourism of history (Sturken 2007), which share the focus on tourism associated with death. As Stone and Sharpley highlight in their seminal study (2008), the field remains limited both in its definition, and with regard to analyses of how Dark Tourism is consumed. Dark Tourism is associated with macabre themes, such as death and suffering (Stone and Sharpley 2008), and as a result, it has been used to frame the study of penal history museums (Ferguson and Piché 2015); Charles Manson Museum (Podoshen et al. 2015); black metal music (Podoshen 2013); and Holocaust memorials in Berlin (Brown 2015), to mention but a few. The most common focus of these studies is on how the tourist is seeking to engage with macabre topics; however, there are historical sites which embrace a twofold meaning: both as reminders of death and shameful pasts, as well as essential episodes in local, national and international historical accounts, having an impact on identity building and sense of belonging of certain communities.

Consequently, recent developments in the literature have begun to move away from a concern with how death is represented and consumed, to a concern with understanding visitor's responses to these representations. For example, Biran et al. (2011) undertook a study of the motivations behind visiting Auschwitz, finding that visitors expressed the idea that they needed to 'see it to believe it', that their visit provided them with 'learning and understanding' as well as the fact that Auschwitz was a 'famous death tourist attraction'. Visitors also privileged the fact that their visit gave them an 'emotional heritage experience' (830). On the basis of these findings, Biran et. al (2011) reached the conclusion that 'it is not death or the dead that should be considered, but living peoples' perception of them' (837), demonstrating how these visitors empathize with the past by connecting with present day concerns.

\section{Experiential authenticity and Memory Museums}

This focus on visitor experiences of Dark Tourism sites aligns well with a parallel critique of notions of authenticity which also effect a move from the object to the subject. The notion of authenticity has been thoroughly questioned by post-structuralist readings (Baudrillard 1983) which argued against more traditional definitions of the term, referring to 'unspoiled, pristine, genuine, untouched and traditional' objects displayed in museums (Handler 1986: 2). This understanding of authenticity is challenged by concepts of phenomenology and hermeneutic 
phenomenology, introduced by Husserl, Heidegger and Gadamer (Laverty 2003), and lately adapted to tourism studies. Heidegger (1962 [1927]) emphasized the idea of Being-in-Time, 'for only "in me" is "time" experienced' (248), shifting the focus from the object to the subject, the awareness of our own experiences. Gadamer moved this concept forward by highlighting the role of language in supporting the consciousness of these experiences (1966: 3). As I shall show, the descriptions of personal visits uploaded in TripAdvisor align with these theories, demonstrating how a reflection of their experiences are synthesized into words, which are then shared with the online community.

Likewise, recent developments in tourism studies have also prioritized understanding visitors' experiences as a form of authenticity above any claims about the authenticity of the object or site they are experiencing. Cohen, for example, argued for this focus by explaining that "[...] most tourists entertain concepts of "authenticity" which are much looser than those entertained by intellectuals and experts, such as curators and anthropologists' (1988: 383). Similarly, Wang highlighted that '[...] if mass tourists emphatically experience the toured objects as authentic, then, their viewpoints are real in their own right' (1999). By shifting the emphasis from the object to the subject (existential authenticity), the visitor is activated through a series of experiences (Selwyn 1996), and the authenticity of the object becomes irrelevant. Museums engaged with the 'material turn' explore the potential of objects in provoking meaning and feelings, activating the role of the visitor: subjective experiences are encouraged by the objects displayed (Dudley 2010: 2).

This shift has been developed in parallel with museums which, with their design features and collections, aim at supporting active experiences. These innovative design museum features, also referred to as interpretative design (MacLeod et al. 2015: 314) revolve around the promotion of experiences and meaning making of visitors (315), highlighting curiosity, challenges, narratives and participation, both physical and dialogic (Skydsgaard et al. 2016). As Heine argues, the 'museum in transition' not only focuses on the experience over the object; this tendency also 'valorizes emotive over cognitive meaning', and as a result, objects should prioritize the evocation of feelings (2000: 79). It is the emotional response in a memory museum which supports empathy and identification with the people from our pasts (Arnold-de Simine 2013: 13).

\section{Prosthetic memory and design features.}

Both case studies, OWM and JMB '[...] encourage visitors to empathize and identify with individual sufferers and victims, as if "reliving" their experience, in order to thus develop more personal and immediate forms of engagement' (Arnold-de Simine 2012: 18). In order to achieve this engagement, the museums represent episodes that move visitors, either through the narrative, the collection, the experience, or a combination of all. The main challenge is to create a personal connection with a historical past which the visitor has not actually experienced. As Landsberg argues, the distance between a past narrative and a present-day visitor can be transformed into a personal and emotional connection through prosthetic memory. This is a form of memory,

[...] which emerges at the interface between a person and a historical narrative about the past at an experiential site such as a movie theatre or a museum. In this moment of contact, an experience occurs through which the person sutures himself or herself into a larger history [...]. The person does not simply apprehend a historical narrative but takes on a more personal, deeply felt memory of a past event which he or she did not live. (Landsberg 2004: 2).

MacDonald has defined these associations between the audience and the past, as 'past presencing', which encompasses the present and the future. These experiences emerged from the consumption of the 'condensed time' of heritage, which supports the intensity of the experience (2013: 234-5). As I shall demonstrate, both museums I discuss create a very strong empathy and prosthetic memory thanks to their narratives and design features, which, combined, can evoke a strong image in the audience. This empathy is legible on the reviews left on TripAdvisor, which align with Lynch's theory on the imageability of the city, adapted here to museums. 


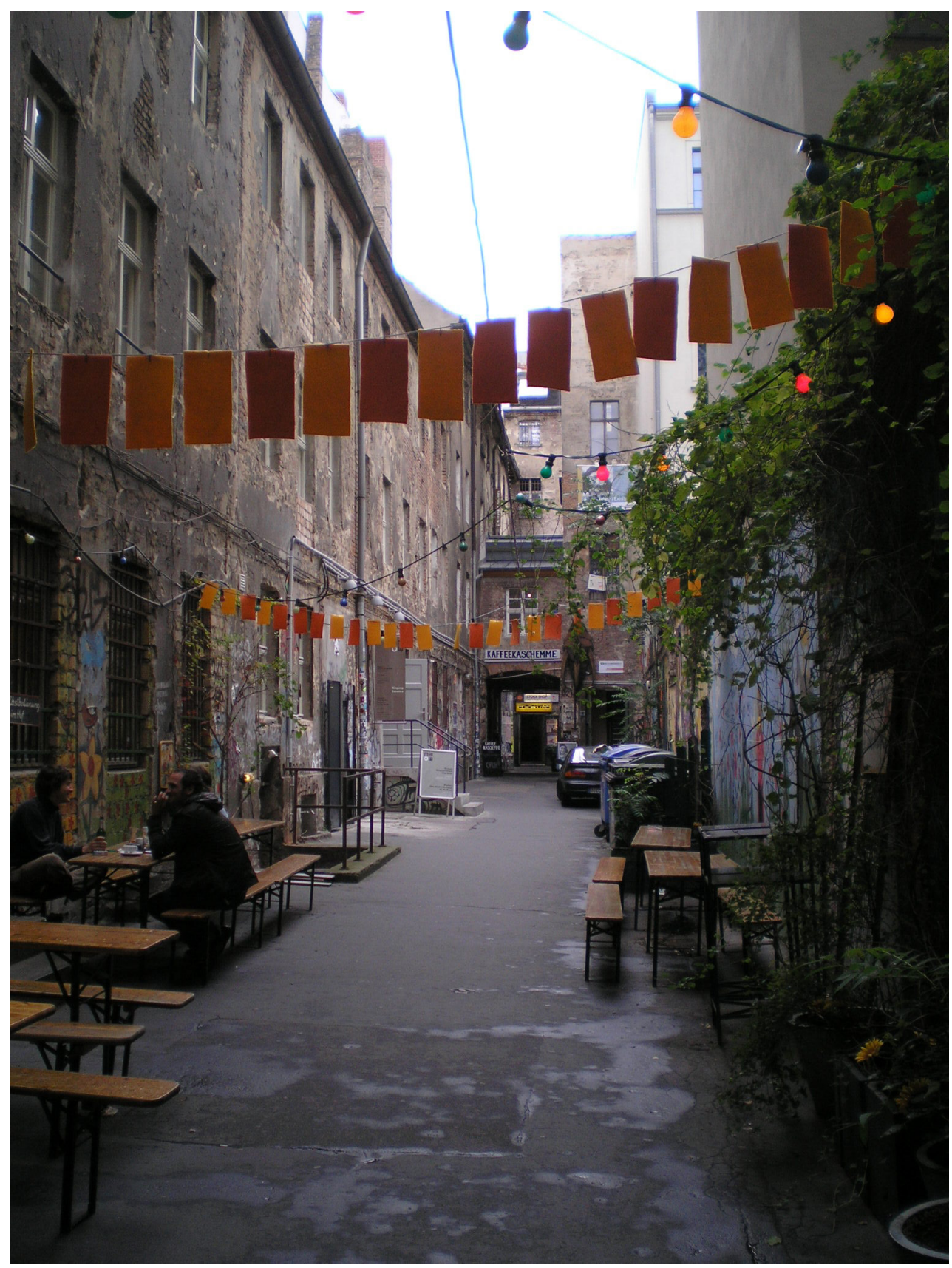

Figure 1: JMB (exterior). Author 2008.

Lynch argues that the city must be understood not just as a thing in itself, but as perceived by its users (1960: 3 ). A visitor can generate a mental picture of a space, as a product of the 'immediate sensation and of the memory of the past experience', which supports the interpretation of the information received (4): 'The observer selects, organises, and endows with meaning what he sees. The image so developed now limits and emphasizes what is seen [...].' (6). 
According to Lynch, there are five main elements which contribute to the legibility and/ or imageability of a city: paths, edges, nodes, districts and landmarks, elements which have been adapted and applied in this article. The fifth category, the landmark, as an external feature, cannot be applied to either museum: the OWM is hidden in a courtyard; the JMB aligns with neighbouring buildings, in spite of its zinc façade.

The path becomes the main element to describe the circulation; the edges are the walls that organize the museum; the districts are the sections within a building; the nodes are strategic points, intensive foci which are enclosed, that can stand as symbols, places created in the convergence of paths (1960: 47-83). The reviews from TripAdvisor show a connection between the paths and districts, as important features to understand the narrative of the museums, and ultimately their experiences. The inclusion of nodes as part of the textual images of these museums reveals a much richer description, which follows high ratings on the TripAdvisor website.

The analysis of the reviews from TripAdvisor is based on the conceptual framework that resulted from the literature review, alongside Lynch's suggestion that clear and strong features create memorable images. Four main themes have been used to frame the analysis of the comments uploaded in TripAdvisor: Experience, Narrative, Architecture, and Recommendations to fellow travellers. All these comments contribute to the imageability of their experiences, with a clear correlation between strong emotional experiences, richness of comments and overall score of the museums.

\section{Methodology}

Netnography is becoming a popular method to analyze data in several disciplines, including tourism studies (Podoshen 2013). Netnography adapts a number of techniques from ethnography, using data from computer-mediated communications and online forums (Kozinets 2010: 60). As a research method, it uses popular techniques from social sciences, including participant observation, and thematic analysis, but adapts them to internet sources as documents (Bryman 2008: 515), using the data of those who 'willingly post thoughts and feelings in a public forum' (Podoshen 2013: 266). As such, these contributions have not been influenced by a researcher (Mkono 2012: 553). Kozinets has categorized different types of online communities: TripAdvisor fits within the 'geeking community' definition, where members share very detailed information, but do not engage in meaningful personal interactions (2010: 32). Despite the benefits of using netnography as a method, there are also noteworthy shortcomings: limited engagement with participants; impossibility to verify the authenticity of participants' claims; and finally, ethical considerations, due to the absence of informed consent (Mkono 2012: 555).

The present study has overcome these challenges since the engagement with the participants (as a 'geeking community') and the authenticity of the claims does not affect the analysis. First, there is no expectation to engage in discussions with other members, in line with the idiosyncrasy of this online community; second, experiential authenticity, is, by essence, personal and emotional, and consequently the veracity of the reviews is not relevant for the study. Finally, the ethical issues were considered within the broader field of netnography, and good practice was identified and followed: the anonymity and confidentiality of the participants is protected by not displaying usernames (Ferguson and Piché 2015: 362).

The comments from TripAdvisor were coded without the aid of automated tools, grouping keywords in main themes, alongside the rating system (between five and one stars, which represent excellent, very good, average, poor and terrible, accordingly). The comments from TripAdvisor have been analyzed thematically, highlighting the connection between design features, the narrative of the museums, and the experiential authenticity as described by the audience, which ultimately is translated into a recommendation of these sites (Table 1). The richness of the comments and descriptions of their emotional experiences convey the imageability of the museums. 


\begin{tabular}{|l|l|l|l|}
\hline Experience & Architecture & Narrative & Recommendation \\
\hline Experience & Architecture & Holocaust & Worth a visit \\
\hline Emotional response & Libeskind & History & Value for money \\
\hline Didactic value & Tower of Holocaust & Memorial & Other \\
\hline Time spent & Circulation & & \\
\hline Confusing & Fallen leaves & & \\
\hline Audio guide & Garden of Exile & & \\
\hline & Axis & & \\
\hline & Voids & & \\
\hline & Stairs & & \\
\hline
\end{tabular}

\begin{tabular}{|l|l|l|l|}
\hline Experience & Museum & Narrative & Recommendation \\
\hline Didactic value & Hidden location & Inspiring story & Worth the visit \\
\hline Moving experience & Size of the museum & Unknown narrative & No fee \\
\hline Time spent & Authenticity & Individual stories & Part of a tour \\
\hline Positive experience & $\begin{array}{l}\text { Appreciation of } \\
\text { museum (unknown) }\end{array}$ & Schindler & E-mouth \\
\hline
\end{tabular}

Table 1. Grouping of keywords and main themes.

\section{Otto Weidt's Workshop for the Blind Museum. Rosenthaler Straße 39, Mitte.}

The original brush workshop on which the Museum is now located was once in a thriving Jewish quarter: in the 1930s there were around 300 Jewish institutions in this neighbourhood (Tuchel 2008: 8). Nowadays, Rosenstrasse and its surrounds in East Berlin is rather trendy thanks to its centrality and amenities on offer, including theatres, museums, restaurants, and shops (Jordan 2006: 127).

The brush workshop was managed by Otto Weidt and manned by blind and deaf Jewish people. During the Third Reich, Weidt and his wife tried to protect the lives of the workmen by bribing the Gestapo and using the back-room as a hide-out. Their efforts were not always successful, and ultimately only part of this community survived the Holocaust (Tuchel 2008: 163). Otto Weidt himself was recognized as a victim of fascism in 1946, before his death in 1947. Afterwards, his wife received a Senate of West Berlin pension, acknowledging her efforts to help victims of persecution during the Third Reich. In 1971, Yad Vashem (the Israeli National Holocaust Memorial) awarded Otto Weidt the recognition of 'Righteous among the Nations' (Tuchel 2008: 163).

The building and the courtyard where the Museum is located remained untouched from 1945 , as a consequence of an inheritance dispute. A group of students took advantage of this context and organised a temporary exhibition in 1999: Blind Trust: Hidden at Hackescher Markt, 1941-43. After several events and visits of prominent politicians, the exhibition became permanent and was managed under the umbrella of the Jewish Museum. Eventually it was transferred to the German Resistance Memorial Centre in 2004. Thanks to funding provided by the federal government and the Berlin Lottery, the Foundation finally acquired the former workshop (2004), supporting its narrative with the creation of the adjacent Silent Heroes Memorial Centre (2008). The location of the museum was especially significant, offering an 


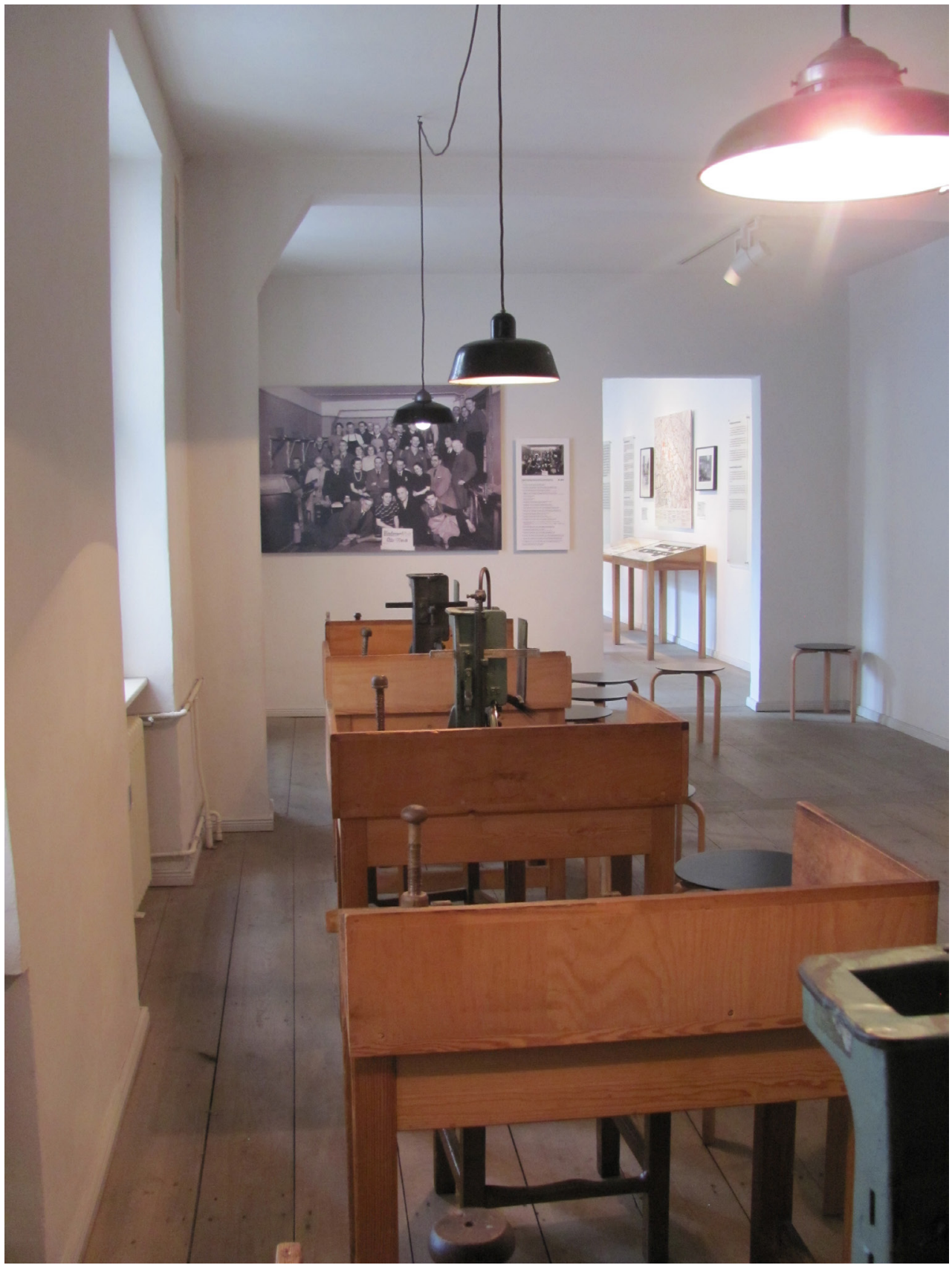

Figure 2: OWM (courtyard). Author 2008.

authentic framing to exhibit a historical event. ${ }^{2}$ The museum itself promotes an experience based on prosthetic memory by combining the authenticity of the place, the small scale of the building, as well as the portrayal of an unknown narrative (Germans as heroes). Dorothée 


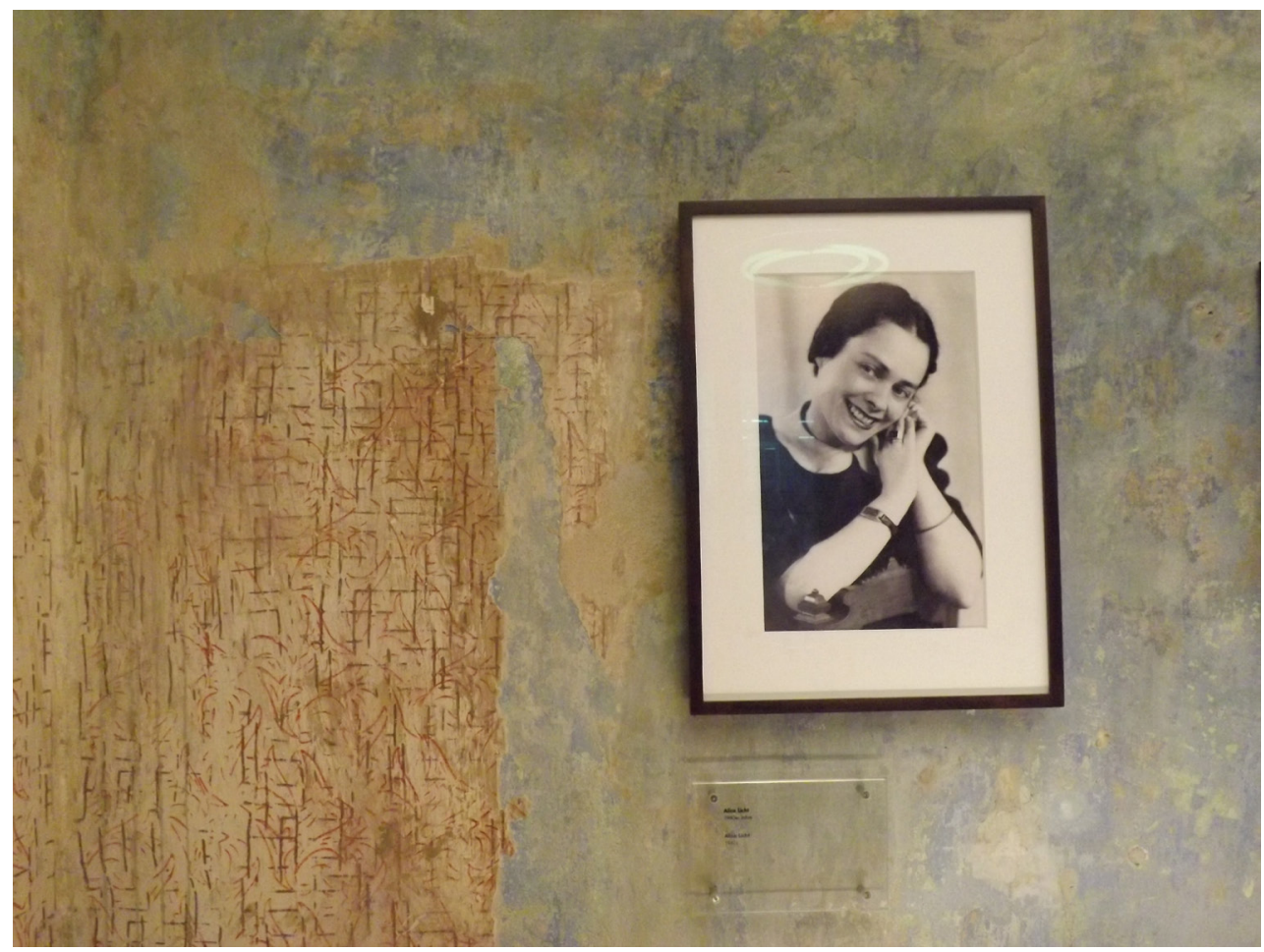

Figure 3: OWM (interior). Author, 2008 \& 2014.

Hauck designed the exhibition, seeking to maintain the authenticity of the space by introducing minimal gestures, such as different lighting and colours in each room, building up, slowly but dramatically, a personal connection with Weidt's story. ${ }^{3}$

There is one main difference with the 1940s factory: the original wardrobe blocking the hide-out does not exist anymore, so Hauck replicated the front, and by cording the sides, blocked the access into the room. ${ }^{4}$ This design choice, despite being remarkably simple is surprisingly effective: it incites an empathic reaction on the visitor, who can only glimpse a fragmented view, reinforcing the idea of an unreachable sacred space, emphasized by the dramatic use of light, recognizable within religious iconography.

Education is at the core of OWM's mission, publishing academic research and 'memoirs' of survivors of the Holocaust, spreading the knowledge of these stories far and beyond. ${ }^{5}$ The visit to the museum, however, remains a challenge: it is not sufficiently signposted; it is excluded from the dominant tourist trail of Berlin; and its location and scale blend with its context. Consequently, the museum has become an invitation rather than an imposition, a place to be searched for. It is ultimately this perception of 'discovering' an unknown space that is referred to many times in the TripAdvisor reviews (Table 1), which ultimately increases its value within this online community:

My friend and I stumbled across this place by accident, but I'm really glad that we did. I have studied a lot of history of this time period but had never heard the amazing story of Otto Weidt, and how he so courageously and selflessly helped so many deaf and blind Jews during that terrible time. It is a small exhibition but it was very moving - definitely worth a visit.( $5^{\star}$ review). 


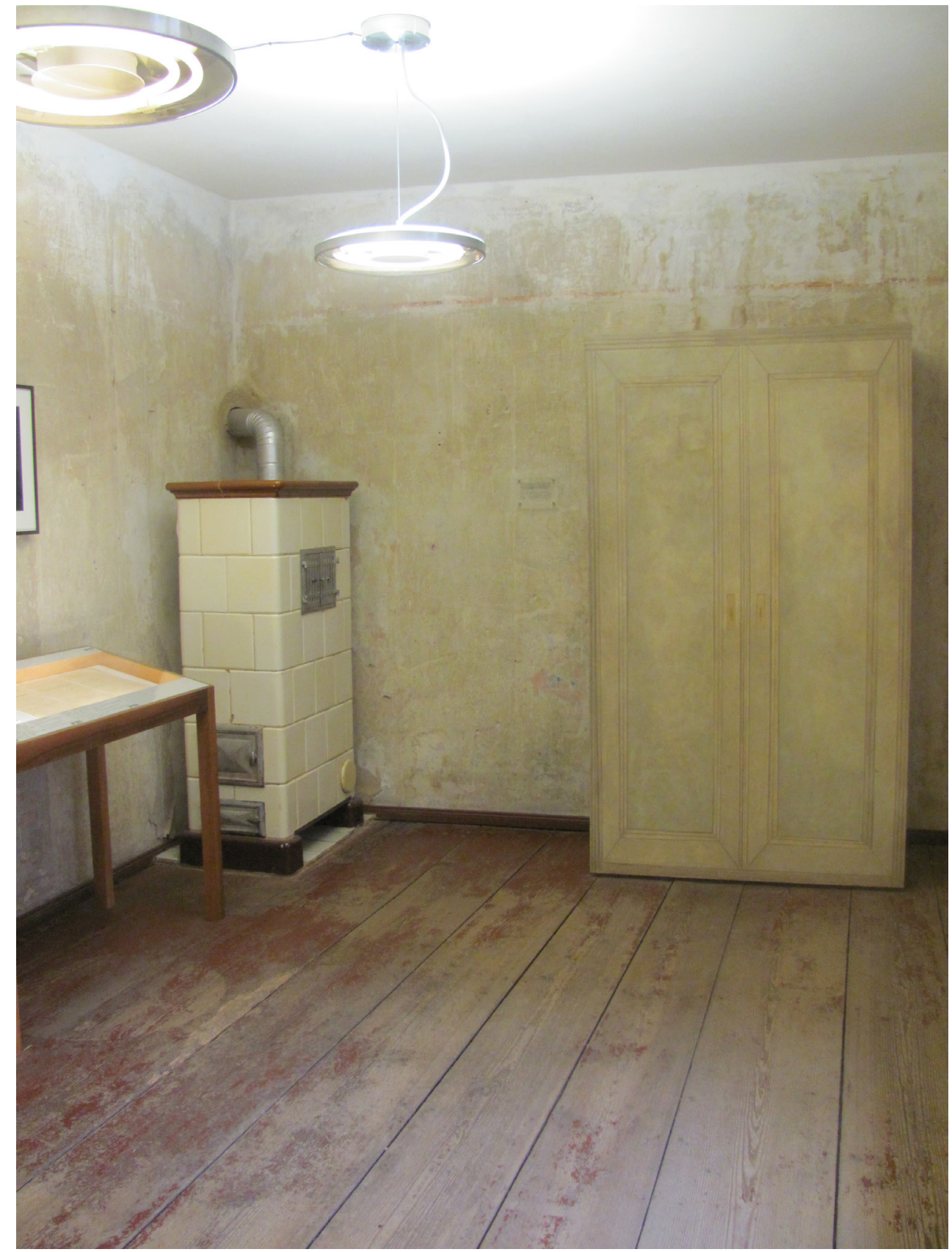

Figure 4: OWM (interior). Author, 2008 \& 2014. 


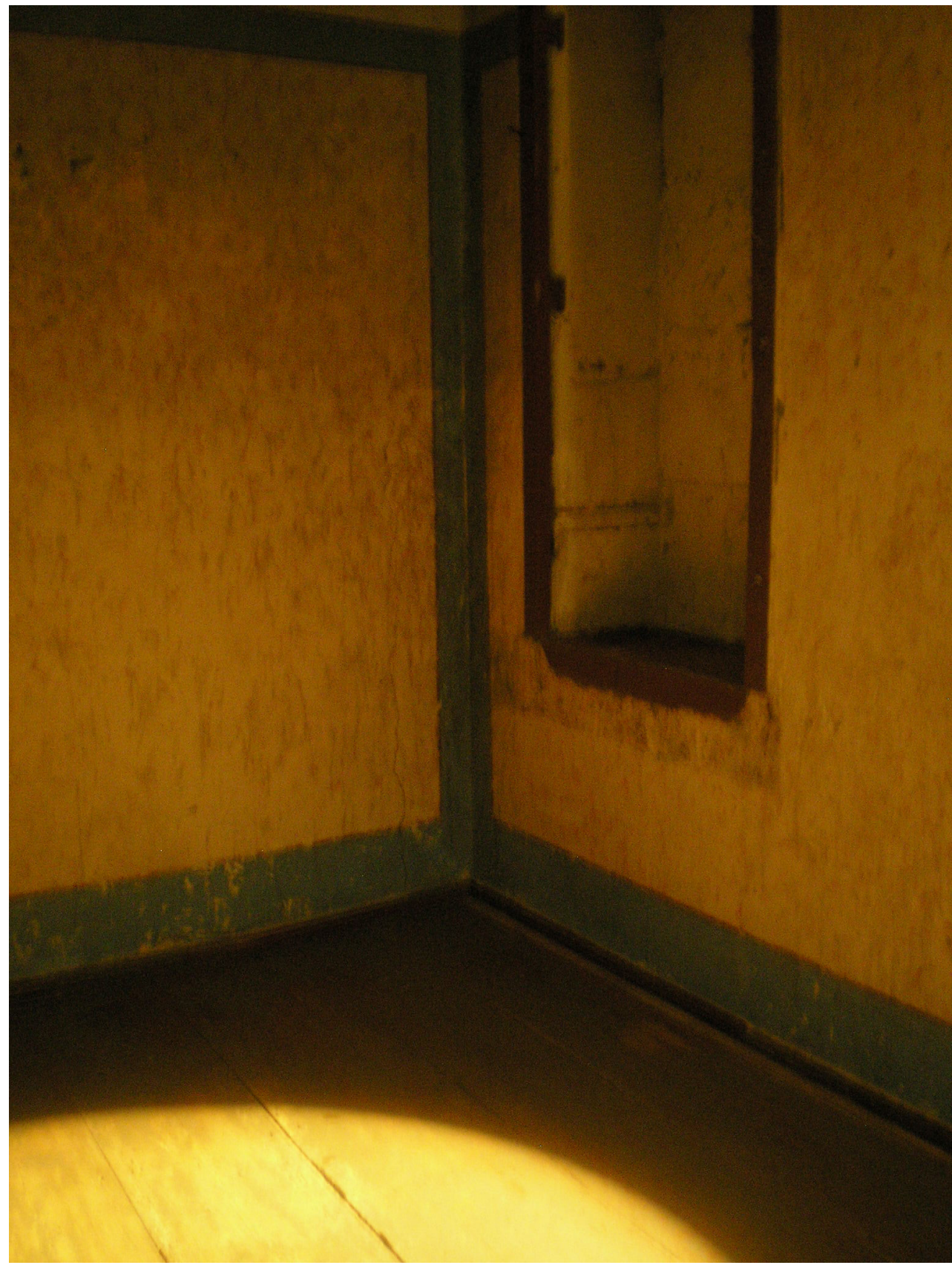

Figure 5: OWM (hide-out room). Author 2008. 


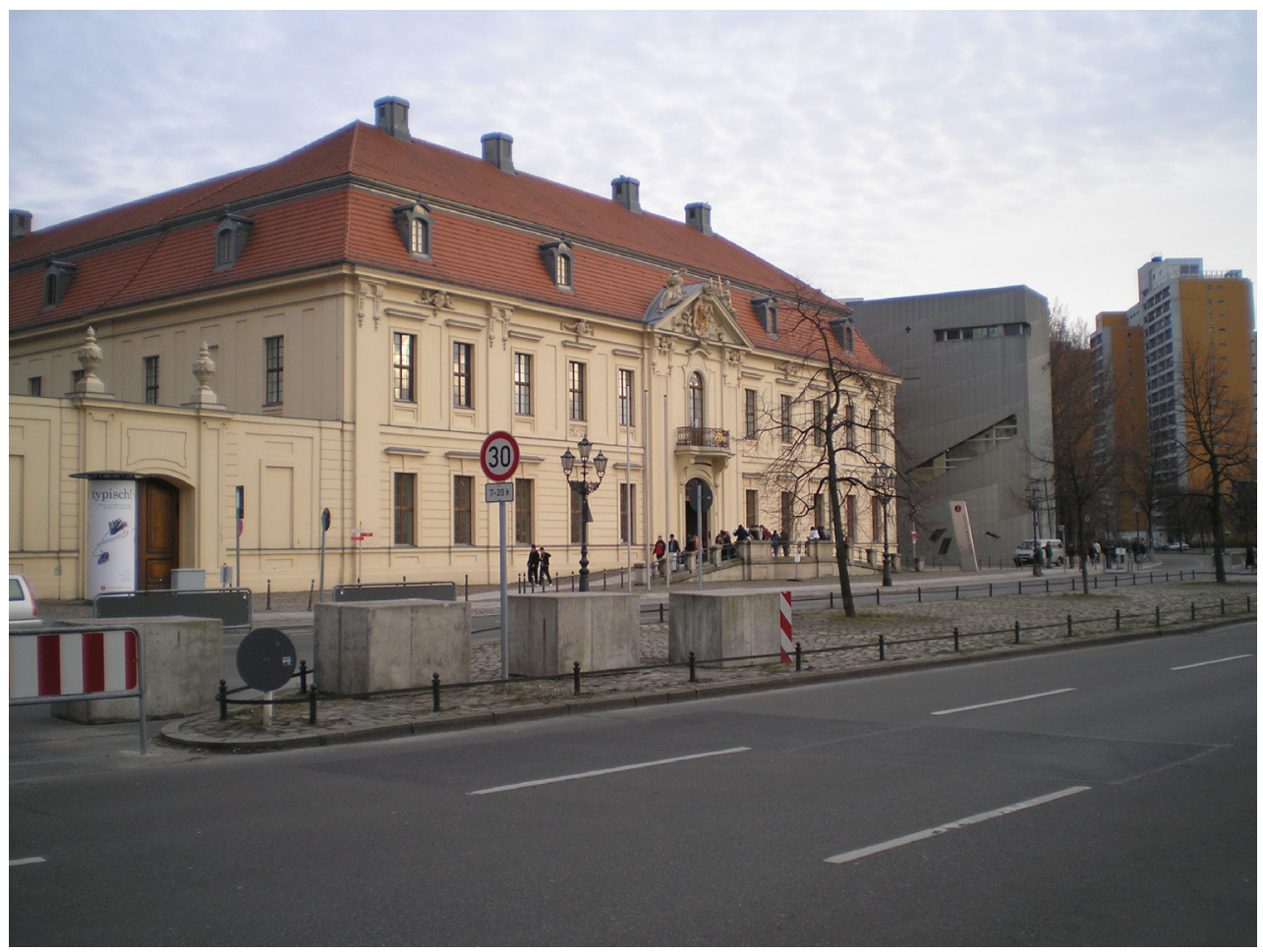

Figure 6: OWM (hide-out room). Author 2008.

\section{Jewish Museum Berlin, Lindenstraße 9-14.}

The JMB has a long and complicated history behind its design, construction and reception. The refurbishment of the Kollegienhaus as the new Berlin Museum in the West, started in the 1960s, with the budget finally approved in 1988. All architects from the Federal Republic of Germany, and twelve international architects were invited to the competition for an extension of the Kollegienhaus: 165 designs were submitted, and Daniel Libeskind's proposal was the favourite one:

The idea is very simple: to build the museum around a void that runs through it, a void that is to be experienced by the public. Physically, very little remains of the Jewish presence in Berlin - small things, documents, archive materials, evocative of an absence rather than a presence. (Libeskind 1992: 85).

Libeskind's project, 'Between the lines', revolves around a matrix of straight but broken lines, which create voids in the intersections (Libeskind 1992: 84-86). These lines show the invisible connections between the addresses of relevant German Jews (intellectuals, musicians, architects, etc.); Arnold Schonberg's incomplete opera Moses and Aaron; a Gedenkbuch (a book with information about deported Jews from Berlin); and Walter Benjamin's One way street (Libeskind 1997: 34). The fall of the Berlin Wall in 1989 created a new context to this project, due to the costly process of reunification. The budget was revised twice, forcing the architect to modify the design since 'the museum has to stand and open itself in a different way in a united and wall-less city' (Libeskind 1997: 113).

Since its opening, the JMB has become an iconic building, receiving 350,000 visitors before it was officially inaugurated (Costello 2013: 7). The scale of the building is overwhelming, although from the street this is not appreciated: the zig-zag structure is only recognized when 


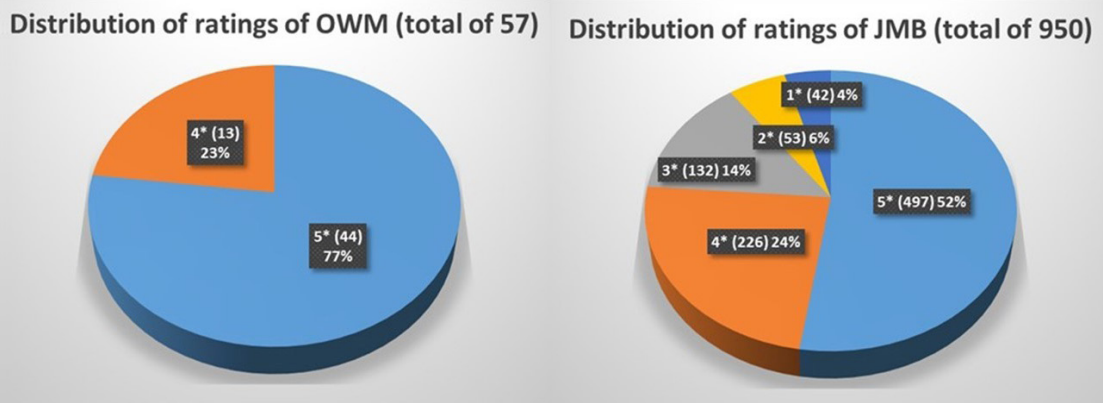

Table 2. Distribution of ratings for OWM (57) and JMB (950).

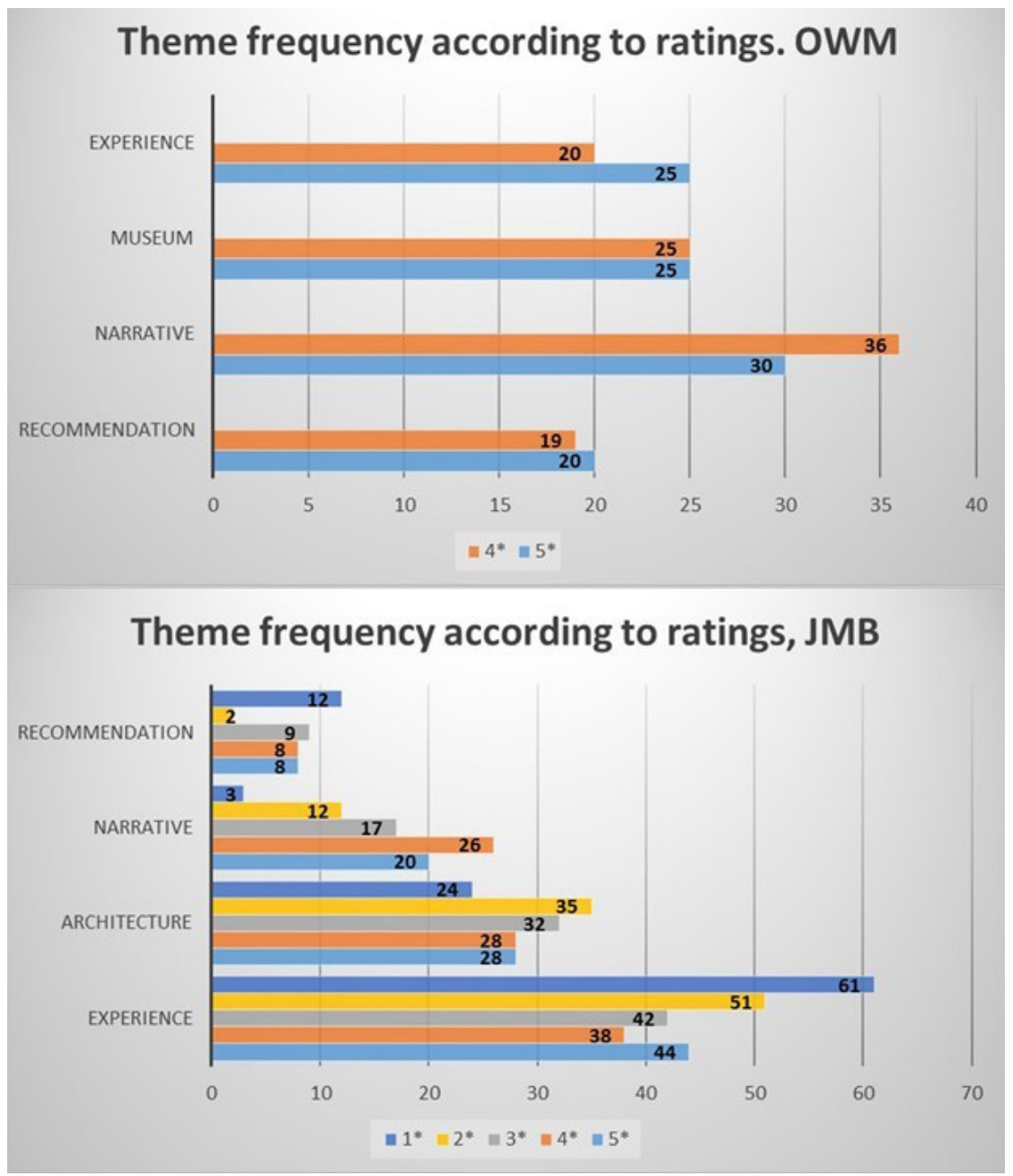

Table 3. Theme frequency according to ratings. 
visiting the top exhibition spaces, since the underground lay-out is different. The zinc-clad façade makes a striking contrast with the Kollegienhaus, which now merely hosts visitor services. Before the Berlin Wall fell, this area of the city was not very affluent due to its proximity to the Wall; nowadays it is a vibrant part of the city, with a diverse population and cultural centre.

\title{
Analysis
}

The analysis is based on 950 reviewers of the JMB and 57 of the OWM, as collated in September 2015 (Table 2). The considerable discrepancy in numbers is a consequence of the JMB being a very popular tourist destination in Berlin (included as a Top 10 destination in most travel websites), ${ }^{6}$ whilst the OWM is mostly an unknown museum and narrative. As a result, the JMB has a wider spread of ratings and comments which also include the management of the museum (long queues for tickets, audio guides and the cloakroom), whilst the OWM only has $5^{*}$ and $4^{*}$, and only positive comments were recorded.

Following the literature review, three main areas were explored in order to extract the main keywords for the thematically analysis of JMB and OWM. The first, from the area of Dark Tourism, centres on the motivation of visitors to visit the site. Even though both museums have been considered as Dark Tourism due to the nature of their narratives, ${ }^{7}$ none of the TripAdvisor reviews mentions a desire to engage with macabre themes (as per Stone and Sharpely's definition). Conversely, visitors rated didactic and emotional experiences very highly, referring to the main narratives (Holocaust and History at the JMB; individual stories and inspiring hero at the OWM) in the majority of the comments (Table 3 ). This tendency aligns with that explored by Biran et al., and Osbaldiston and Petray, who, as referred to above, argue that learning about history was at the core of the motivation behind visiting sites connected with death.

The significance of encounters with personal stories rather than objects comes through very strongly in both museums. For example, this TripAdvisor review of the OWM underlines the significance of learning about individual stories, not through the exhibition of objects: 'This museum should be as vital to visit as any of the other holocaust memorials. It's about real people not things. The impact is huge and lasting. It's a MUST'. Likewise, the Jewish Museum has received comments which highlight the didactic nature of this institution: 'Berlin has an important history to share on the events of the Third Reich and its impact on the vibrant Jewish community in Berlin. A visit to the museum can broaden your understanding of this story'.

The second and third themes, experience and memory, coming from the review of literature on tourism and memory studies, are intimately connected with the use of design features to reinforce empathy and prosthetic memory. These topics are quite entangled in the reviews, especially in those regarding the JMB:

\begin{abstract}
A very emotive museum that really portrays the feelings of hatred toward Jewish people in the Holocaust. Very well designed to use architecture and exhibitions to make you think deeply. The dark room and the room with the metal faces are must-see features - extremely powerful places. Visit! ( $5^{\star}$ review).
\end{abstract}

Even though this reviewer fails to remember the names of the Tower of the Holocaust and the Fallen Leaves installation, the description is still very powerful, and creates an overall image of the museum that embodies the way its narrative is produced through strong emotional and didactic experiences that are enhanced by design features. Ultimately this is summed up by a recommendation to visit the JMB.

The thematic analysis has unveiled a clear connection between vivid experiences (with most frequent themes being architecture, narrative and experience), higher rating $\left(5^{*}\right.$ and $\left.4^{*}\right)$, and more detail in the reviews (Table 4), as proposed by Lynch and the theory of hermeneutic phenomenology, whereby language is essential to express an experience.

In regards to the $\mathrm{JMB}$, in the $5^{*}$ group most entries describe positive experiences, both experiential and didactic. These comments offer rich descriptions of the narrative of the museum, and how the design features support it, increasing the empathy within the visitor. The scarcity of original objects, and the random location of the museum, create the opportunity for a staged authenticity which reinforces the connection between the narrative and the visitor. 

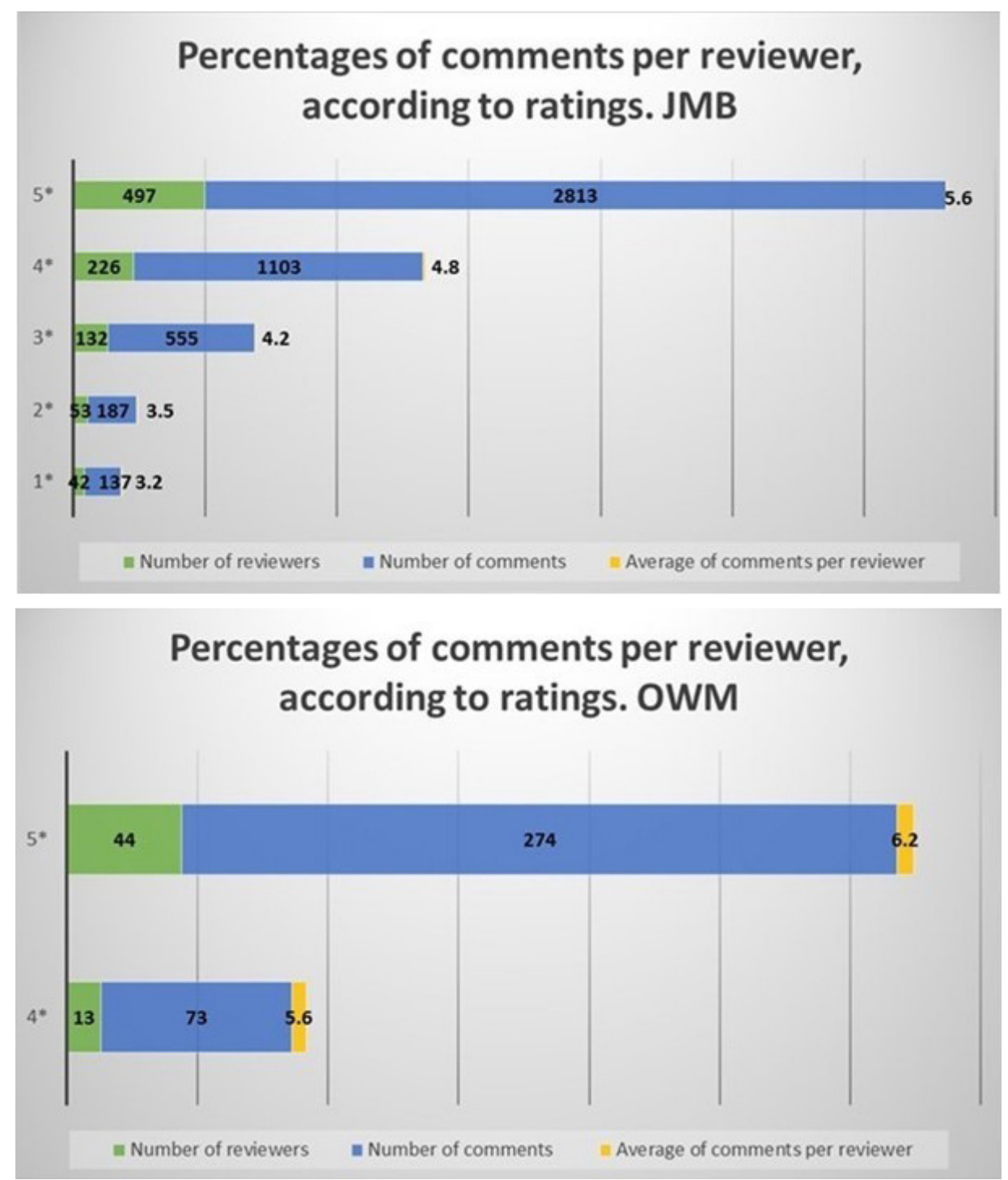

Table 4. Average of comments per reviewer.

The main design feature is its circulation, which, together with the description of the main nodes (Fallen Leaves, Tower of Holocaust, Garden of Exile), are mentioned by many visitors in the $5^{*}$ section (Table 5).

Libeskind explained in his proposal how he wanted the visitor to be an active participant (1992: 84). As a result, the circulation of the JMB is not straightforward: first, the main entrance directs visitors to the services area; the exhibition starts underground, three paths leading to three different narratives: Berlin's history (the axis of continuity, resumed on the top floor levels); the path to exile (towards the Garden of Exile), and the dead-end path, culminating in the Holocaust tower. This underground plan creates a narrative of its own, enhancing the prosthetic memory of the Holocaust 'on a mental, visceral and emotional level' (Libeskind 2000: 25). These elements were mentioned by many visitors, as features which enhanced (and in some instances hindered) the experience of the museum. 


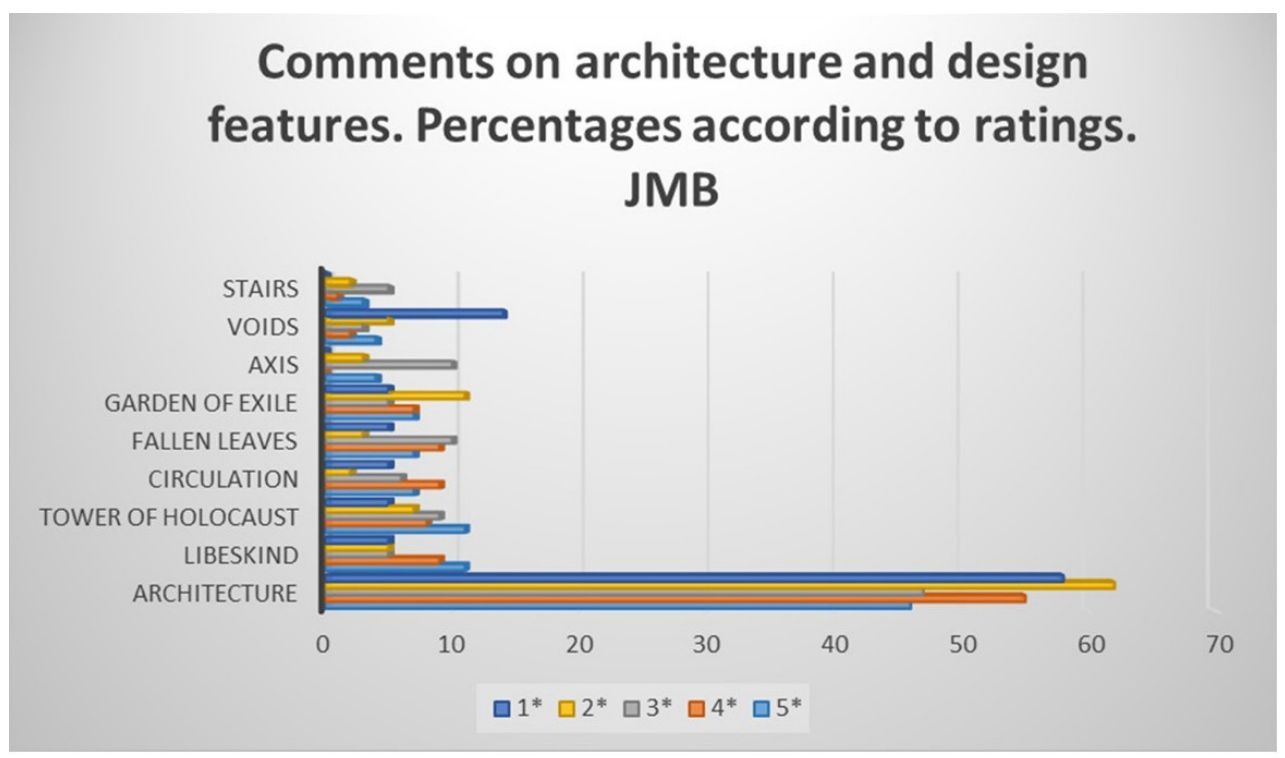

Table 5. Correlation between architectural detail and ratings (frequency percentage).

Comments regarding the confusing circulation infer a connection between the $4-5^{*}$ ratings and visitors interested in authentic experiences (the subject), and those in the $1-3^{*}$ who were more interested in an educational visit (the object). Many visitors embraced the circulation as a challenge, as something interesting and valuable:

Once you're inside, the layout of the first floor is deliberately confusing. This is an artistic decision - one which l'm sure you can decipher. The pathways weave all over the place and there appears to be no specific direction to take. I really liked this aspect as it definitely added to the feel they were going for. The story of the people affected by the holocaust is shown here and it is extremely touching. (5* review).

This is contested by other reviewers, which assigned a lower rating for the exact same feature: 'The building was awful, confusing and really put me off. Almost impossible to navigate!' (3* review).

The circulation also instigates a sense of disorientation in the upper floors, with a zigzag path, crossing bridges and voids throughout the exhibition. When the museum opened in 2001, the visitors were bewildered by this, and the management responded with red floor markings and arrows (Grodzinski 2002: 13). Instability is ever present: the nodes, districts and edges have been designed to promote this sensation throughout. The edges, organizing the space, add to the awkwardness: voids that cannot be crossed, only looked into from the corridors; bridges that are not apparent; art installations that block paths ('The Gallery of the Missing' by Lewandowsky); or walls that are not straight, that create dead-ends. They all contribute to the generation of a sense of unsettlement, reinforced by the districts and nodes.

According to Lynch, a node is a strategic spot, a place created at a junction, a crossing, like a square (1960: 47). The main nodes in the JMB are the Holocaust Tower, the Memory Void with Menashe Kadishman's art installation Shalechet (Fallen Leaves), and the Garden of Exile: these spaces frame unique experiences, identified by numerous visitors. JMB's corridors serve both as paths and exhibition spaces, where people engage with the objects showcased. However, in the nodes, the visitor is expected to be active to fully comprehend the space and its meaning: there are no objects in these spaces, the emphasis is on the void created by the edges (the walls), especially in the Holocaust Tower. 


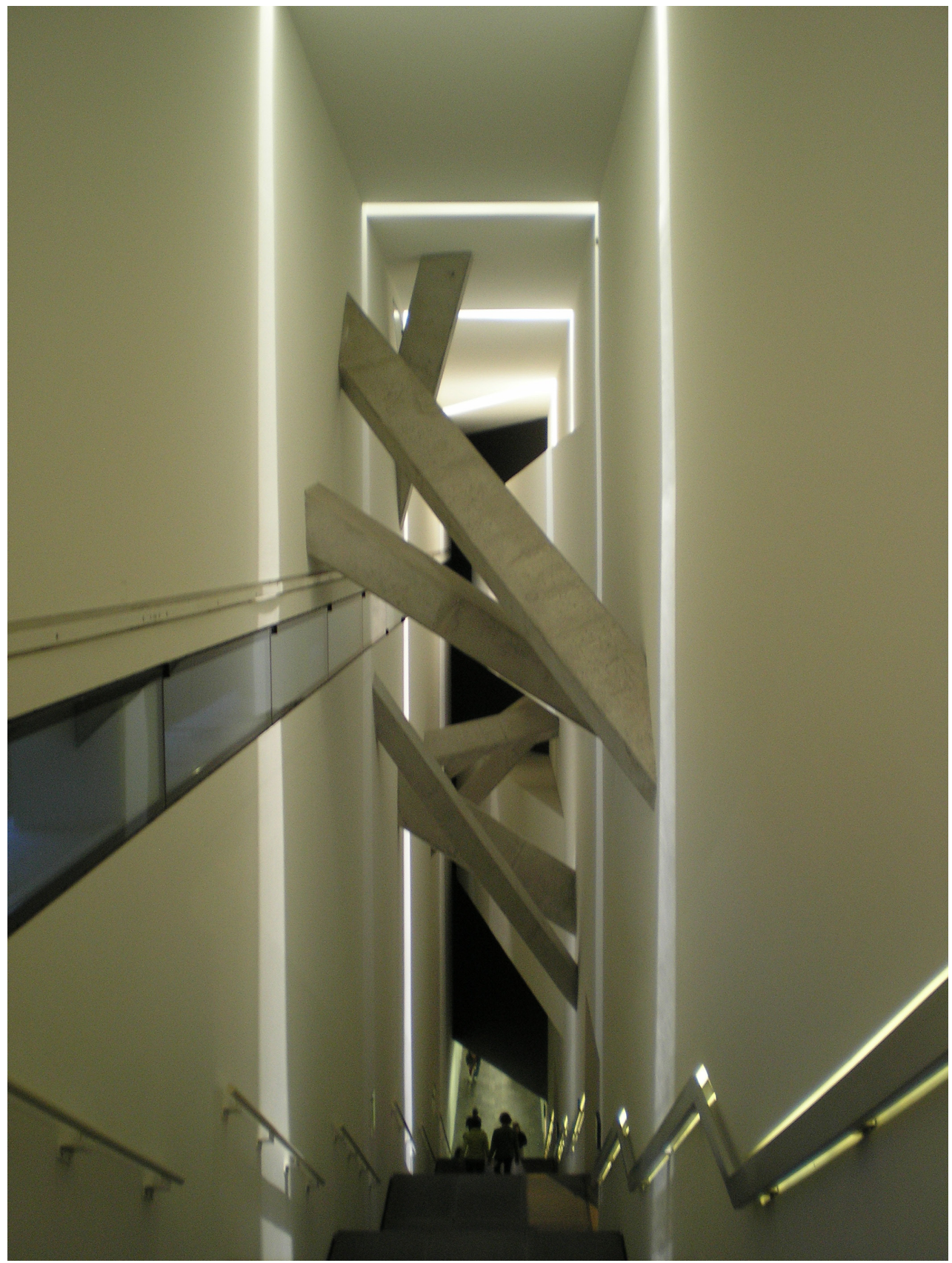

Figure 7: The Axis of Continuity. (Author 2012) 


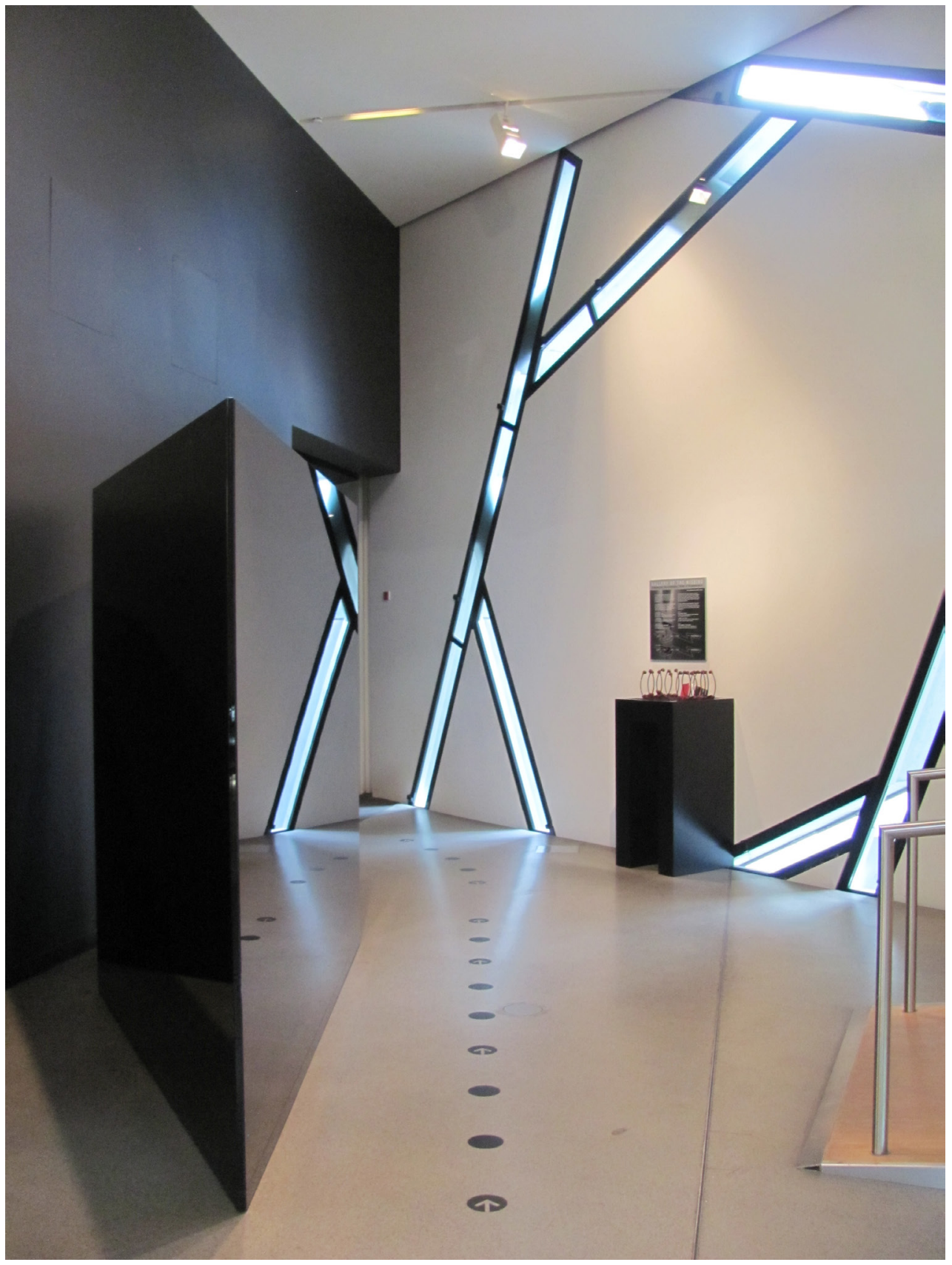

Figure 8: Interior JMB. (Author 2008) 


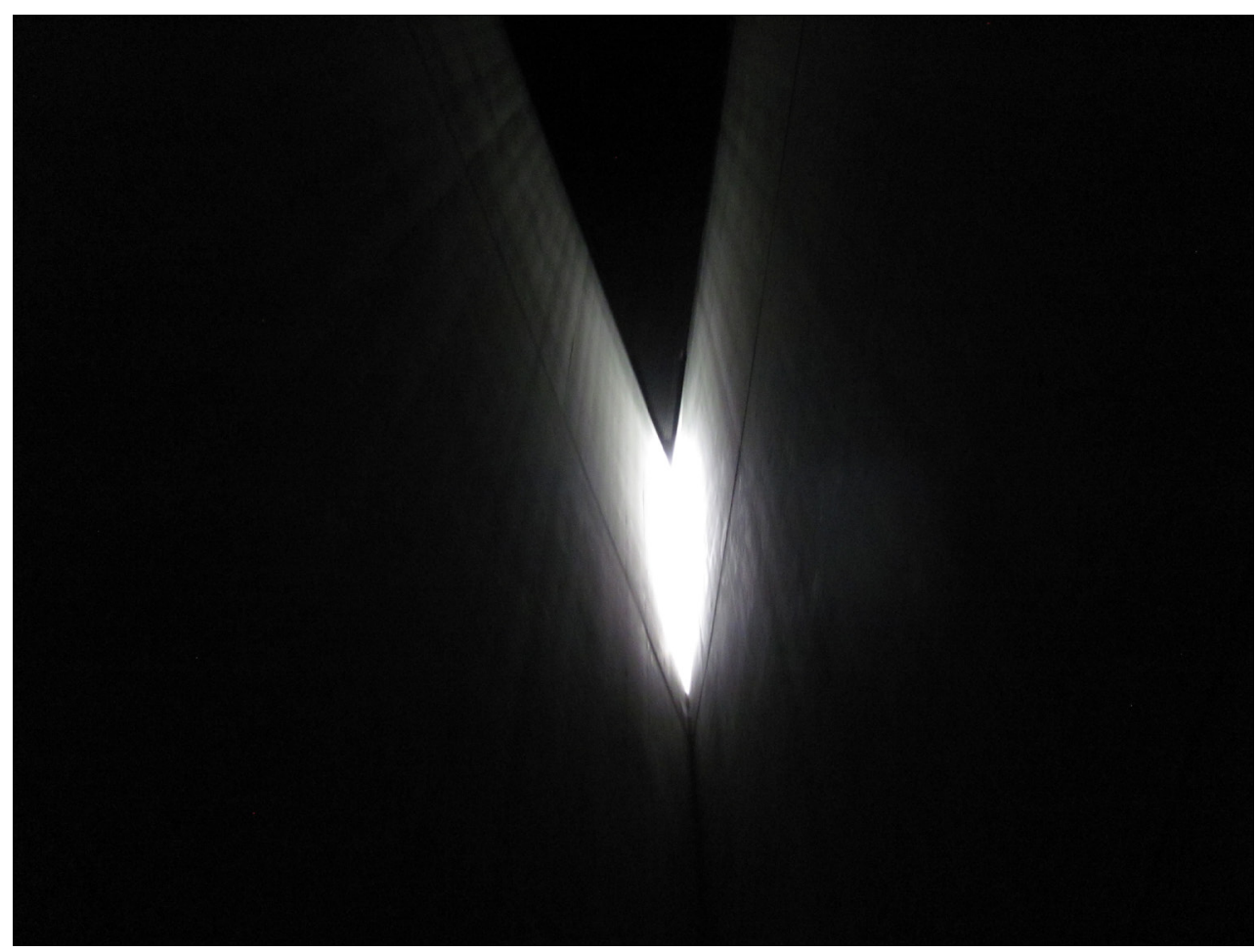

Figure 9: The Holocaust Tower. Author 2012

This tower, originally named the Void of Voids, is a pentagonal space created by bare concrete walls, and a roof with a narrow opening shedding natural light. There are no objects, only an unreachable ladder. In order to reinforce the phenomenological nature of the space, this tower is unheated, so the temperature contrasts with the rest of the museum. Moreover, one feels disconnected from the world, even though it is possible to hear outside noises, children playing nearby. It is a space that does not promote dwelling, its uncanniness pushes the visitor to feel extremely uncomfortable and leave the space promptly: it creates prosthetic memories of suffering, 'quite scary and very moving' (5* review).

The ETA Hoffman Garden of Exile is another node: a space to dwell and experience the feeling of displacement: a 'shipwreck in history, [...] disturbing, unstable' (Libeskind 1999: 41). The path leading outside is inclined and decreases in height towards the end, forcing a very expressive and narrow perspective, leading to the sunken garden. The 49 pillars, filled with earth from Berlin and Jerusalem, are perpendicular to the floor, which is tilted in order to add to the feeling of instability.

The last main node is the Memory Void, left empty by Libeskind, currently occupied by the installation Shalechet, or Fallen Leaves, by Israeli artist Menashe Kadishman (19322015), who dedicated it to the victims of the Holocaust, and to all victims of violence. When the visitor is confronted with such a space (three levels high, several meters deep), with the floor covered by thousands of metal faces which portray suffering, prosthetic memory of the Holocaust is established. The experience of walking on top of art, together with the noise that the metal makes, adds to the feeling of guilt at stepping on suffering faces. Moreover, it is rather difficult to walk under these conditions, activating a certain survival instinct. As pointed out by Metz, this walk: 
Is also about spectatorship: it asks us to question not only what kind of human being walks on others, but what kind of human watches such stomping and does nothing. Who is the more barbaric? I found this whole experience utterly devastating. (Metz 2008: 34).

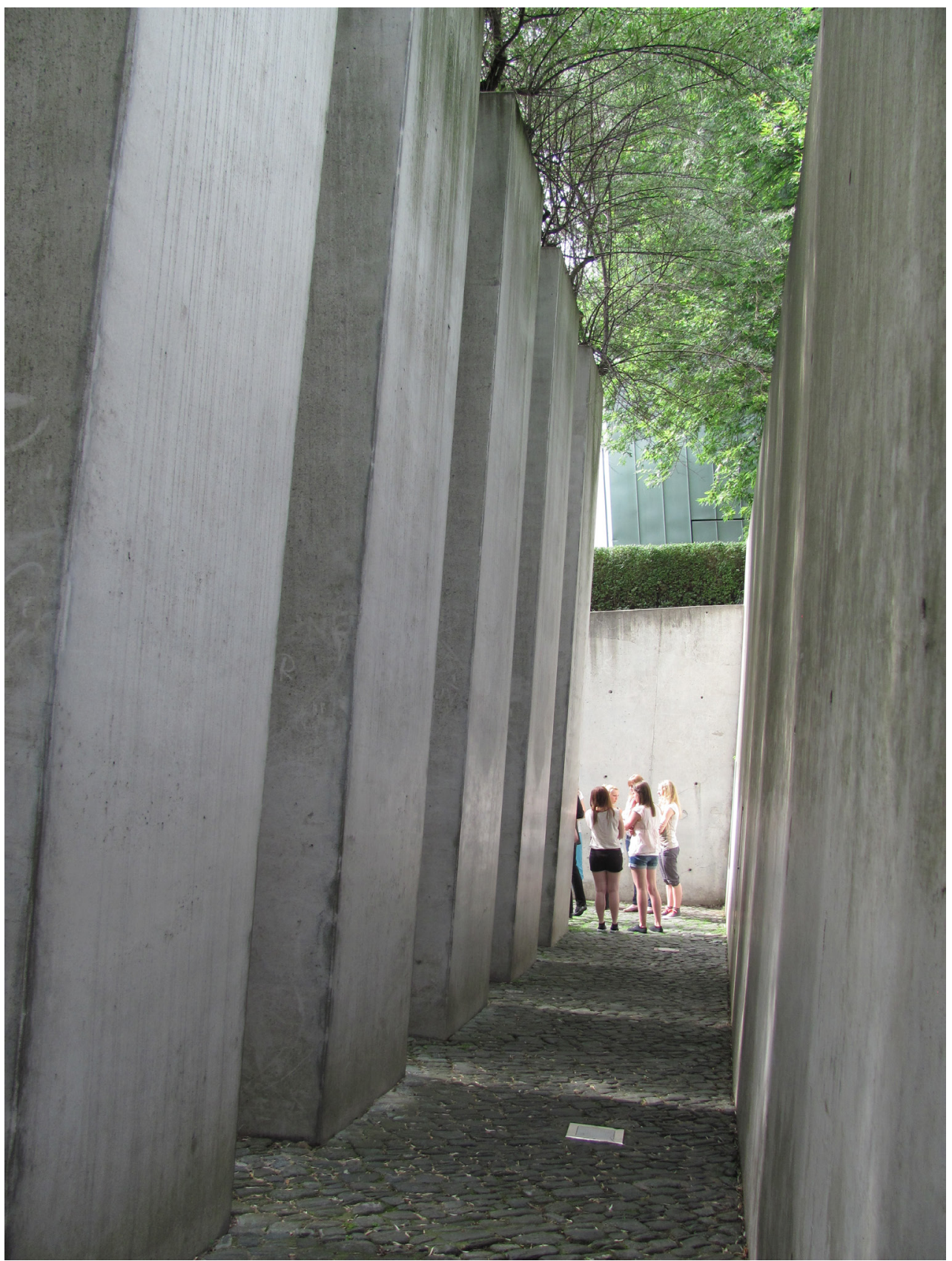

Figure 10: Garden of Exile. Author 2012 


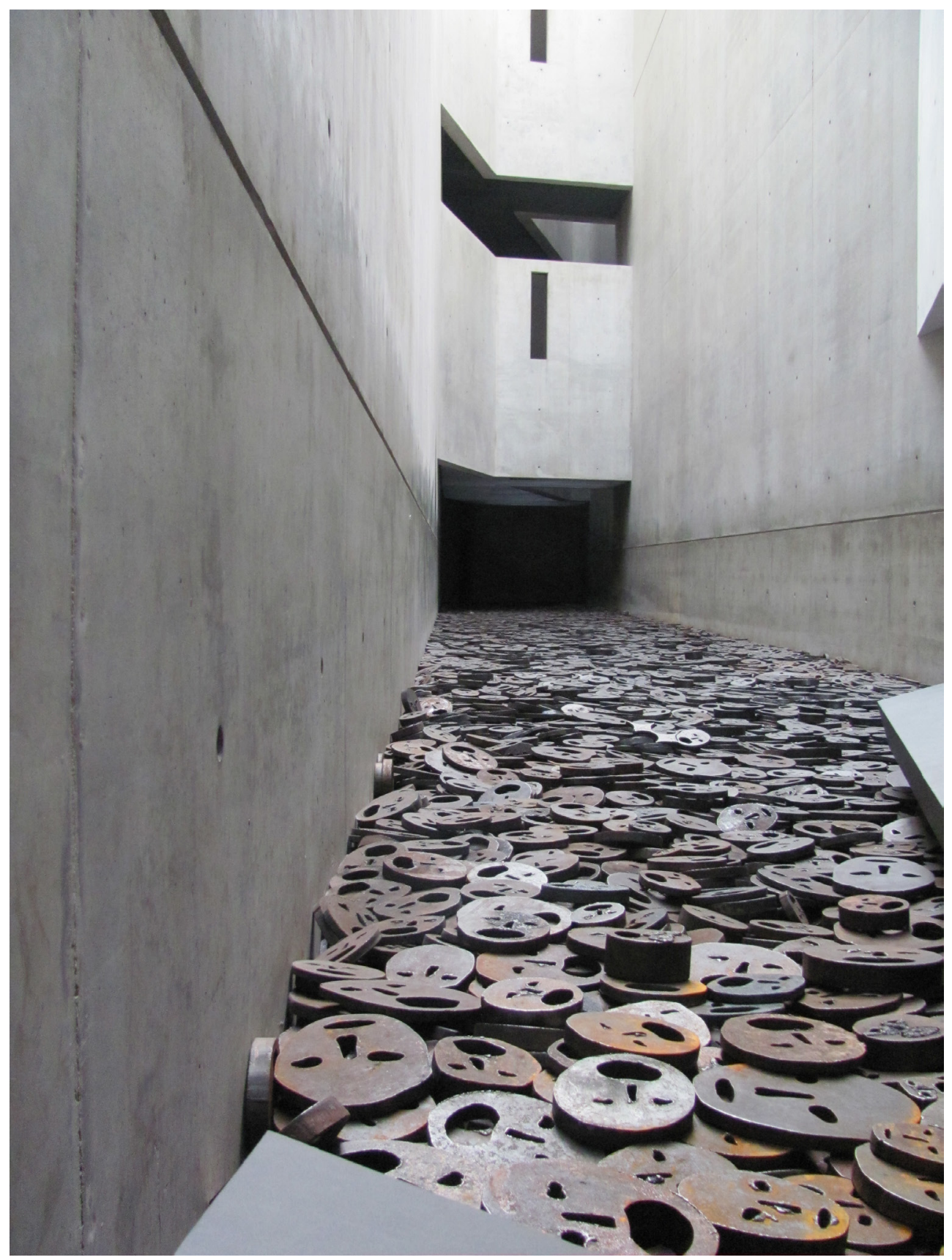

Figure 11: Fallen Leaves. Author 2012.

In 2001, the management dissuaded visitors from waking on Shalechet due to insurance concerns. Groclzinski was relieved by this situation, wondering whether people would wish to undertake such a walk if allowed (2001: 20). However, comments from TripAdvisor reveal how the majority of visitors were moved by this experience, and encouraged others to do the 
same: "The sound... people walking on the tortured "faces", the coldness of the space itself and the grey, steel walls surrounding the faces made for such a strong experience. It is truly unforgettable' (5* review).

The perception of the main narrative is also connected with the detailed descriptions of the architectural features: most of the $5^{*}$ reviews mention architecture in general, and/or specific details, such as the architect's name, his nationality, the style of architecture, etc. Similarly, many reviews refer to the main foci of the museum: the Garden of Exile, the Tower of Holocaust, the Fallen Leaves, as well as the axis in the underground floor, the voids and the stairs leading to the top floors (Table 5). There is also a very common observation within these comments: the provocation of thoughts, emotions, and feelings, highlighting how the architecture was extremely moving (Table 3 ).

Some comments included a comparison with other buildings in Berlin, such as the Holocaust Memorial (similar to the Garden of Exile), the Museum of History (regarding the main collection), as well as the Reichstag (for its symbolism). There are also observations about similar design features in other museums such as the Holocaust Museum in Washington, or the Yad Vashem Museum in Jerusalem. The foci within the different districts of the JMB promotes a double narrative which was picked up by many of the comments on the $5^{*}$ rating:

In the first part, you walk through the memory of holocaust. It's a lot of silence, and empty space, and dark. It's just space for feeling to come, and realize what we as human beings were able to do to other human beings. [...] The second part of the museum is dedicated to the history of Jewish community in Germany. (5* review).

In the $4^{*}$ section fewer reviewers mentioned the architectural features, and even though most comments complimented the design, many entries described the architecture as 'too clever', 'overshadowing the collection'; a few responses criticized the circulation being 'too confusing', 'too challenging', 'distracting': several visitors missed part of the collection due to the odd layout. The comments in the $3^{*}$ section reinforce concerns about the building: 'architecture becomes a distraction', 'the circulation is too confusing (atrocious!)', 'there is a disconnection between the underground space (more geared towards the Holocaust theme) and the top two floors (about the history of the Jews)', 'the underground being very interesting, whilst the rest (the collection) is not', 'terribly designed', 'useless museum', 'pretentious', 'fancy', and 'weird',

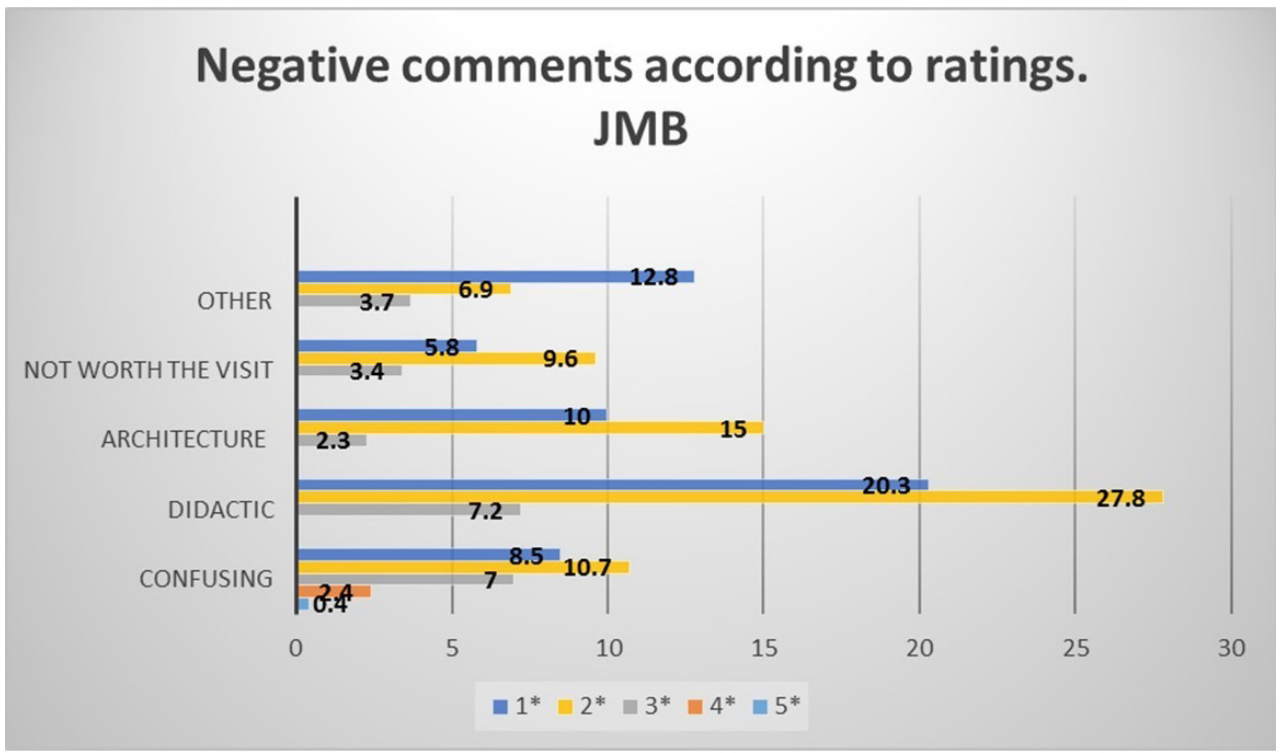

Table 6. Negative comments according to ratings. JMB. 
to quote but a few comments. The $2^{*}$ and $1^{*}$ section offers a range of adjectives to describe the museum, such as 'boring', 'schizophrenic architecture', 'cold and sterile', 'poor content', 'poor layout', 'lack of meaning in the confusing layout', 'not enough about the Holocaust', 'too modern' (Table 6). The recommendation of other buildings reinforces the criticism of the JMB: the Holocaust Memorial and the Topography of Terror are viewed as better (free) options to learn about the Holocaust.

The entries on the JMB show a clear connection between the experience of the museum and the imageability as uploaded in TripAdvisor. Most visitors enjoyed the experience as a positive challenge, promoting their curiosity with uncommon design features, such as the circulation and its boundaries; and the foci within the different districts of the museum, reinforcing the narrative of the JMB (the Holocaust, the Jewish contribution to Berlin, or both). Fascination with death is never acknowledged: if anything, there are comments about the importance of learning about these episodes and remembering them (educational and moral); always reinforced by the authentic experience which increases the prosthetic memory of the visit.

The OWM reviews are mostly positive since the visitors had no expectations: most comments reveal how they stumbled upon the museum, and as a result, were very impressed by the space and the narrative. Most reviews recommended it as good value for money: no queues, no fees, unknown narrative which reinforces the didactic and moral result of the visit, an original space that promotes reflection:

This museum throws light on the underground side of the German war that is very rarely spoken off. The ordinary Germans who risked their lives so their Jewish neighbours and friends could have a chance of surviving. Many who helped did not get recognition for their heroism, this museum tries to right that wrong. A must to see. $\left(5^{\star}\right.$ review).

The descriptions of the design features are not as rich as those of the JMB, but they recognize the authenticity of the space, with its 'rough walls', 'you cannot tell they have been renovated at all', housed in the 'former factory'. Similarly, the circulation is described as 'calm, effective and informative', a 'logical layout'. The OWM has a very simple circulation, but for the attentive visitor, the journey encompasses more than just walking through a corridor; the first room has been designed to provide a general background: neutral, informative, showcasing objects that support the information provided on the panels. Moving down the corridor, there are fewer artefacts, and the rooms focus on stories of individual people. The coloured walls, which are in a deliberately poor state of repair (highlighting the authenticity of the place), set the context for the display of those who were hidden during Gestapo raids.

That is the end of the corridor: the hide-out has been concealed by the front of a wardrobe; the room is empty, no more objects or personal stories are told. That is the authentic space where people hid in the hope of surviving the Holocaust. This empty space promotes the empathy that will create a prosthetic memory in the visitor: 'The museum/exhibition was so touching and thought provoking, I must admit to having a lump in my throat and could have easily got emotional whilst there' (5* review).

The OWM is based on simple circulation, exhibition and decor: one corridor serves as path, edges, and districts. The node, the intensive foci of this museum, is the hide-out room: the emptiness of the space, is similar to the staged authenticity of the voids in the JMB. The physical characteristics (the focus on the space rather than on the objects) support the authenticity of the narrative, and as a consequence, a clear image of the museum, a sense of empathy and transfer of prosthetic memory emerges: 'There's tragedy as well as triumph, but the overriding feeling is one of gratitude and immense respect for what this brave man did' (5* review).

Both museums shift from the traditional approach (didactic showcasing of objects), towards phenomenological narratives which promote prosthetic memories. The OWM addresses this situation by highlighting the authentic appeal of the space, creating a vivid experience and memory of the event: 'The rooms were restored as close as possible to the original with its creaking floor boards, painted walls, ovens and occasional work benches which further personalized the experience. Definitely worth the visit if you are in the area' (5* review). 
The JMB promotes similar feelings through its design: 'The exhibits bring to life the Jewish experience, good and bad, and the building serves the story well' ( $5^{*}$ review). The OWM and JMB do not fit within the Dark Tourism definition: first, the data collated in TripAdvisor does not suggest any connection with a fascination with death, leading to the second reason: a predominant theme within the comments refers to educational concepts, as well as its value as a tourist site (Tables 1 and 3 ).

\section{Conclusion}

'Where the Jewish Museum impresses you with his architecture, this museum [OWM] struck us with the minimalism of the sad but true story'. (5* review).

The aim of this article was to explore how the narrative of museums can enhance prosthetic memory with the support of architectural features. In order to do so a multidisciplinary approach was embraced, combining concepts from memory and tourism studies, as well as museum design. The identification of these concepts, drawn from the academic context, was applied to the main themes identified in online reviews, demonstrating the importance of contrasting theoretical propositions with visitors' perceptions. This analysis has demonstrated that the concept of authenticity does not revolve only around the original nature of objects, but includes the nature of visitor's experience in a museum. Moreover, there is a manifested correlation between strong empathy during the visit of the museums, and the description and ratings in TripAdvisor.

Concerning the OWM, the prosthetic memory was enhanced by a clearly defined narrative, a simple circulation, and a very powerful climax. In the JMB, the authentic experience and consequently, the prosthetic memory, came as a result of the circulation, and the bodily experience of entering the different nodes. The focus of the reviewers in TripAdvisor was not necessarily on the nature of the objects exhibited (authentic, replicas, or technological imagery), but on themselves as subjects. The experience of the museums, through its design features, had a significant impact on the reviews.

The conceptual framework used to analyze both museums has enabled a reading that touched upon motivation behind tourists' visits; the connection between the narratives represented in each museum, as well as the design features which support them; and, finally, the imageability of the museums as described in the TripAdvisor entries. As a result, the main themes which emerged in the literature review have been contrasted with those coming from the audience, with compelling results. Regarding the main motivation behind these visits, none of the reviews refers to concepts connected with Dark Tourism; instead, numerous reviewers highlighted the relevance of the museums in connection to didactic and moral issues, as well as the experience itself. Similarly, a majority of comments referred to the circulation and design features enhancing (and a few times deterring) the museum experience (focused on the didactic element, the prosthetic memory or both). Netnography has been fundamental to demonstrate the imageability and legibility of these museums, highlighting the importance of understanding the audience in order to analyze museums (both their content and design). Ultimately, not many people will ever read Daniel Libeskind's or Dorothée Hauck's explanation of their designs, or even interpretations offered by academics: the main audience for these spaces are the visitors, and their voices should be heard loud and spontaneous.

The episode represented in both case studies is the Holocaust; however, the narrative that they portray is completely different. The OWM focuses on an individual who protected his Jewish workers from the Gestapo. The most important feature of this museum is the authenticity of the space and objects, which reinforces the relevance of the location. This emotional journey is especially augmented when reaching the hide-out room: the space of hope, almost a sacred space where prosthetic memory can be achieved.

On the other hand, the JMB offers a double narrative, which seems rather contradictory. Firstly, the collection explores the contribution of the Jewish community to Berlin. The top floors display individual stories, art work and objects (originals, replicas and audio-visuals) supporting this narrative, including a small section devoted to Nazi Germany and the Holocaust. Secondly, the architectural design is mostly focused on the Holocaust, stressing a very specific episode 
in the long trajectory of the Jewish community in Berlin. This double narrative of the container and the collection has created confusion and disappointment among academics (Grodzinski 2002; Barris 2008), visitors and journalists alike (Klein 2001).

Both the JMB and the OWM shift the focus from the object to the subject, emphasizing the 'emotional investment rather than the historical knowledge' (Arnold-de Simine 2012: 15). My study of these two museums supports the argument that this focus on providing emotional experiences, enables visitors to develop a stronger sense of empathy, by engaging with prosthetic memory. As memory museums, both promote 'a unique, tangible, and sometimes physical, dialogic communication with its audiences' (Costello 2013: 1), transforming visitors from passive bystanders to active witnesses (2013: 18).

Despite the main difference between these two museums (location, scale, narrative, design features), it seems apparent that they both manage to create powerful authentic experiences through the performative nature of their design. They both achieved what Pallasmaa believes to be the most important architectural experience: 'the sense of being in a unique place' (1998: 9). Ultimately, this uniqueness left clear images in the memory of visitors, demonstrating how both museums are legible, and consequently, successful in the creation of authentic images and memories.

Received: 23 February 2016

Finally Accepted: 27 March 2018

\section{Notes}

1 Trip Advisor, Europe - Germany - Berlin - Berlin -Things to do https://www.tripadvisor.co.uk/, accessed 20 September 2015.

2 Museum Otto Weidt's Workshop for the Blind, Europe - Germany - Berlin - Berlin - Things to Do - Museum Blindenwerkstatt Otto Weidt http://www.museum-blindenwerkstatt.de/en/ first-of-all/, accessed 17 February 2016.

3 Dorothée Hauck, 'Project 12', http://www.dhauck.de/, accessed 17 February 2016.

4 Dorothée Hauck, 'Project 12', http://www.dhauck.de/, accessed 17 February 2016.

5 Museum Otto Weidt's Workshop for the Blind, Home-Welcome http://www.museumblindenwerkstatt.de/en/first-of-all/, accessed 17 February 2016.

6 History Museums in Berlin: JMB is number four; and number 13 of 223 Museums in Berlin 4 in TripAdvisor https://www.tripadvisor.co.uk/Attractions-g187323-Activities-c49-t30-Berlin. $\mathrm{html}$, whilst the OWM is number 108 of 916 things to do in Berlin https://www.tripadvisor.co.uk/ Attraction Review-g187323-d594412-Reviews-Museum Blindenwerkstatt Otto WeidtBerlin.html. The JMB appears as number two on the top ten museums in Berlin, according to TripSavvy https://www.tripsavvy.com/top-museums-in-berlin-1520064; top 10 things to do in Berlin in the LonelyPlanet guide https://www.lonelyplanet.com/germany/berlin/traveltips-and-articles/top-10-berlin-experiences/40625c8c-8a11-5710-a052-1479d2776935 and number 11 in PlanetWare http://www.planetware.com/germany/top-rated-museums-andart-galleries-in-berlin-d-zzz-11.htm, accessed 9 January 2018.

7 The website Dark Tourism includes both museums. OWM has been rated 2 black stars, and 3 in the darkometer rating: 'Not too much in the way of artefacts or other classic museum pieces - it's more the authenticity of the rooms themselves that matters here'. The JMB has been rated with 4 black stars, and 3 in the darkometer rating: 'From a specialist darktourism perspective it has to be conceded that some may well find the sections about the Holocaust etc. too brief. But then again, you have to remember that this is not intended to be a specialist Holocaust memorial museum and that that dark chapter of Jewish history in Germany and Europe was only one of many, even if it was the definitively darkest chapter ever'. http://www.dark-tourism.com/index.php, accessed 2 January 2018. 


\section{References}

Arnold-de Simine, S. (2012) 'Memory Museum and Museum Text. Intermediality in Daniel Libeskind's Jewish Museum and W.G. Sebald's Austerlitz', Theory, Culture \& Society, 29 (1) 14-35.

(2013) Mediating Memory in the Museum. Trauma, Empathy, Nostalgia, New York: Palgrave Macmillan Memory Studies.

Barris, R. (2008) 'Architectures of Memory and Counter-memory, Berlin and Bucharest', the annual Ralph and Ruth Fisher Forum: Interpreting Emotion in Eastern Europe, Russia and Eurasia, University of Illinois, June 19-21, www.radford.edu/rbarris/.../Architectures\%20of\%20Memory\%201.pdf

Baudrillard, J. (1983) Simulations, New York: Columbia University.

Biran, A., Poria, Y. and Oren, G. (2011) 'Sought Experiences at (Dark) Heritage sites', Annals of Tourism Research, 38 (3) 820-841.

Brown, L. (2015) 'Memorials to the victims of Nazism: the impact on tourists in Berlin', Journal of Tourism and Cultural Change, 13 (3) 244-260.

Bryman, A. (2008) Social Research Methods, Oxford: Oxford University Press.

Cohen, E. (1988) 'Authenticity and Commoditization in Tourism', Annals of Tourism Research, 15, 371-386.

Costello, L. A. (2013) 'Performative Memory: Form and Content in the Jewish Museum Berlin', Liminalities: A Journal of Performance Studies, 9 (4) November 2013.

Dudley, S. (2010) Museum Materialities. Objects, Engagements, Interpretations, New York and London: Routledge.

Ferguson, M., Piché, J. and Walby, K. (2015) 'Bridging or fostering social distance? An analysis of penal spectator comments on Canadian penal history museums', Crime Media Culture, 11 (3) 357-374.

Gadamer, H.G. (1977) Philosophical Hermeneutics, Berkely: University of California Press.

Grodzinski, V. (2002) '2,000 years of German Jewish History. The Berlin Jewish Museum's first birthday', The Jewish Quarterly, winter (3) 9-16.

Handler, R. (1986) 'Authenticity', Anthropology Today, 2 (1) 2-4.

Heidegger, M. (1962 [1927]) Being and Time, New York: Harper \& Row.

Hein, Hilde S. (2000) The Museum in Transition. A Philosophical Perspective, Smithsonian Institution Press: Washington and London.

Jordan, J. (2006) Understanding Urban change in Berlin and Beyond, Stanford: Stanford University Press.

Klein, J. (2001) 'The Jewish Museum Berlin: Amid Clutter, at odds with itself', The Chronicle of Higher Education, 48 (11) 1-8.

Kozinets, Robert V. (2010) Netnography. Doing Ethnographic Research Online, London: Sage. 
Landsberg, A. (2004) Prosthetic Memory. The transformation of American Remembrance in the Age of Mass Culture, New York: Columbia University Press.

Laverty, S. M. (2003) 'Hermeneutic Phenomenology and Phenomenology: A Comparison of Historical and Methodological Considerations', International Journal of Qualitative Methods, 2 (3) 21-35.

Libeskind, D. (1992) 'Between the Lines: The Jewish Museum, Berlin', Research in Phenomenology, 22 (1) 82-87.

(1997) Architecture and Writings. Radix-Matrix, Munich: Prestel.

(2000) The Space of Encounter, Italy: Universe Publishing.

Lynch, D. (1960) The Image of the City, Massachusetts: The MIT Press.

MacDonald, S. (2013) Memorylands. Heritage and Identity in Europe Today, New York: Routledge.

MacLeod, S., Dodd, J. and Duncan, T. (2015) 'New museum design cultures: harnessing the potential of design and 'design thinking' in museums', Museum Management and Curatorship, 30 (4) 314-341.

McCrone, D., Morris A. and Kiely, R. (1995) Scotland - the Brand: The Making of Scottish Heritage, Edinburgh: Edinburgh University Press.

Metz, W. C. (2008) 'Show me the Shoah! Generic Experience and Spectatorship in Popular Representations of the Holocaust', Shofar: An Interdisciplinary Journal of Jewish Studies, 27 (1) 16-35.

Mkono, M. (2012) 'Netnographic tourist research: the internet as a virtual fieldwork site', Tourism Analysis, 17 (4) 553-555.

Osbaldiston, N. and Petray, T. (2011) 'The role of horror and dread in the sacred experience', Tourist Studies, 11 (2) 175-190.

Pallasmaa, J. (1998) 'The Geometry of feeling -a look at the phenomenology of architecture', Zlaty Rez, 18, 4-9.

Podoshen, J. S. and Hunt, J.M. (2009) 'Animosity, collective memory, rumour and equity restoration: consumer reactions to the Holocaust', Consumption markets and Culture, 12 (4) 301-327.

Podoshen, J. S. (2013) 'Dark tourism motivations: Simulation, emotional contagion and topographic comparison', Tourism Management, 35, 263-271.

Podoshen, J. S., Vivek Venkatesh, Jason Wallin, Susan Andrzejewski and Zheng Jin (2015) 'Dystopian dark tourism: an exploratory examination', Tourism Management, 51, 316-328.

Selwyn, T. (1996) 'Introduction', in Tom Selwyn, ed., The Tourist Image: Myths and Myth Making in Tourism, 1-32, Chichester: Wiley.

Skydsgaard, M., Andersen H.M. and King, H. (2016) 'Designing museum exhibits that facilitate visitor reflection and discussion', Museum Management and Curatorship, 31 (1) 48-68.

Stone, P. and Sharpley, R. (2008) 'Consuming dark tourism: A thanatological perspective', Annals of Tourism Research, 35 (2) 574-595. 
Sturken, M. (2007) Tourists of History. Memory, Kitsch ad Consumerism from Oklahoma City to Ground Zero, USA: Duke University Press.

Tuchel, J. (2008). Museum Otto Weidt's Workshop for the Blind Translated by Karen Margolis, Berlin: German Resistance Memorial Center Foundation. .

Wang, N. (1999) 'Rethinking authenticity in tourism experience', Annals of Tourism Research, 26 (2) 349-370.

${ }^{*}$ Dr. Ana Souto plays a key role in the development and leadership of the research modules on undergraduate and postgraduate courses in Architecture; supervising PhD students and leading the ADBE Professional Doctorate suite.

Ana's research interest lies in architecture as a cultural manifestation of national identity and memory. Ana is currently involved in an interdisciplinary project which deals with ideas connected with identity, memory and culture, using a participatory methodology. This project aims to show the role of culture (with a special emphasis in art and architecture) in promoting a connection between current issues of our times and the past.

Postal Address:

Dr. Ana Souto

School of Architecture, Design and the Built Environment

Nottingham Trent University

Arkwright Building, room 114.

Goldsmith Street

Nottingham NG1 4BU

E-mail address: ana.souto@ntu.ac.uk

Telephone number: 01158486041 